\title{
Diogo Seixas Lopes: Sinal vital
}

Ana Luiza Nobre

Ana Luiza Nobre é Doutora em História pela Pontifícia Universidade Católica do Rio de Janeiro (PUC-Rio, 2008). Possui Graduação em Arquitetura pela Universidade Federal do Rio de Janeiro (UFRJ, 1986), Mestrado em História (PUC-Rio, 1998) e Especialização em Tecnologia, Arquitetura e Cidade (Politecnico di Torino, 1995). É professora do Departamento de Arquitetura e Urbanismo e do Programa de Pós-graduação em Arquitetura da PUC-Rio, e Pesquisadora CNPq e Faperj. Coordenou o Programa de Pós-Graduação em Arquitetura da PUC-Rio em 2012-13, tendo sido responsável por sua implantação. Atualmente coordena o Là - Laboratório de Análises Arquitetônicas, vinculado ao mesmo programa, onde desenvolve pesquisa sobre a relação entre a arquitetura e o chão. Foi pesquisadora visitante na Faculdade de Arquitectura da Universidade do Porto (FA UP, 2019) e sua publicação mais recente é "Arquitetura Atlântica: deslocamentos entre Brasil e Portugal" (em coorganização com João Masao Kamita, ed PUC-Rio/Romano Guerra, 2020).

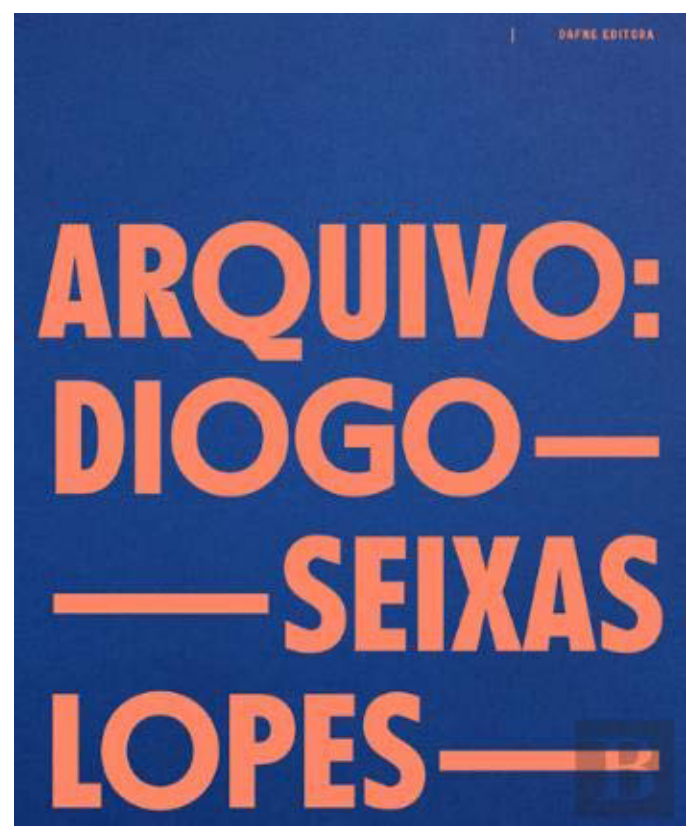

TAVARES, André; LOPES, Diogo Seixas. Arquivo: Diogo Seixas Lopes. Porto: Dafne, 2019, 856 pp. Prémio Design de Livro 2020 DGLAB/Ministério da Cultura, Lisboa

$\mathbf{P}$ ouco se sabe no Brasil acerca da arquitetura portuguesa contemporânea para além das obras consagradas de Álvaro Siza e Eduardo Souto de Moura e de um punhado de outros bons arquitetos - quase todos homens - sediados entre as cidades de Lisboa e Porto. Em parte, tal desconhecimento se deve a uma concertada operação política-cultural cuja expressão mais evidente, nos últimos tempos, foram as retrospectivas simultâneas, em 2019-20, dos dois Pritzkers, parceiros e amigos em duas das instituições mais influentes de Portugal em termos de arquitetura, ambas sediadas na região do Porto (Siza na Fundação Serralves, Souto de Moura na Casa da Arquitectura). Há mais no panorama contemporâneo português, porém, como mostra o livro recém-lançado pela Dafne Editora: uma frondosa monografia do arquiteto português Diogo Seixas Lopes (1972-2016), editada por seu amigo e interlocutor André Tavares (TAVARES, André e SEIXAS LOPES, Diogo. Arquivo Diogo Seixas Lopes, Porto: Dafne Editora, 2019).

Além de terem dividido a curadoria da IV Trienal de Lisboa, em 2016 - numa parceria interrompida pelo falecimento precoce de Seixas Lopes, a meio caminho da organização do evento - Diogo e André se torna- 
ram vozes fundamentais no concerto da arquitetura de Portugal por compartilhar uma postura crítica rara, sem receios de se tornar incômoda em alguns momentos. No mapa das intricadas relações políticas e sociais que permeiam o meio da arquitetura portuguesa, certamente terá contado sua filiação: Diogo é filho de dois intelectuais ancorados em instituições chave da cultura lisboeta (o cineasta Fernando Lopes e a jornalista Maria João Seixas), e André é filho do arquiteto e historiador Domingos Tavares, professor emérito da prestigiosa Faup/ Faculdade de Arquitetura da Universidade do Porto. Nem por isso sua atuação pode ser deduzida de seus laços sanguíneos, porém. Como se percebe pelo livro, o que mais conta é a relação aguda, ao mesmo tempo de pertencimento e estranhamento, mantida por um e outro com relação ao país em que nasceram e onde se formaram arquitetos - o primeiro na Universidade Técnica de Lisboa, o segundo na Universidade do Porto.

Não por acaso, o histórico das relações entre os dois desenha um mapa que vai muito além das fronteiras de Portugal. Foi no CCA/Centro Canadense de Arquitetura, onde em 2011 se reencontraram como pesquisadores, que se intensificou a interlocução que este livro consagra. O tom celebrativo e mesmo ambicioso da publicação, desde sua caracterização como um "arquivo", só pode ser entendido sob o prisma desse diálogo intelectual, nascido de um esforço crítico comum. Um esforço que envolve uma série de deslocamentos geográficos, inclusive, mas não só.

O "Arquivo: Diogo Seixas Lopes" segue uma lógica não-seletiva, com uma estrutura parcialmente cronológica. Reúne, organiza e disponibiliza, em cinco seções, um conjunto bastante heterogêneo de trabalhos (basicamente textos, mas também alguns desenhos) publicados e não publicados do autor em torno de temas ligados à arquitetura, ao cinema, às artes plásticas e à música, entre 1989 e 2015. Dos escritos para periódicos, iniciados com a colaboração regular do autor para o jornal lisboeta Já, nos anos 1990, o leitor pode assim ir e vir entre histórias em quadrinhos, roteiros de filmes, textos críticos, entrevistas e textos relacionados à própria obra projetual de Seixas Lopes (desenvolvida em parceria com a arquiteta e companheira Patrícia Barbas no atelier Barbas Lopes, sediado em Lisboa, que tem no seu currículo projetos realizados como o Teatro Thalia - com Gonçalo Byrne - e a controversa torre FPM 41, ambos na capital portuguesa).

O tom crítico se manifesta claramente em vários momentos do livro. Um dos textos mais rutilantes nes- 
te sentido tem mais de 20 anos e intitula-se "E não se pode criticá-lo?" (Já, 1996). Nele, o autor começa se perguntando que grau de liberdade ele mesmo teria ao resenhar uma exposição de Álvaro Siza então em curso no Centro Cultural Belém. A questão não estaria tanto em contestar a relevância do percurso do arquiteto mas a consensualidade erigida em torno da sua obra: uma obra que "ou é de tal forma axiomática que elimina qualquer exercício analítico e se auto-impõe universalmente ou então concluímos que grassa qualquer comodismo por parte de quem (não) a examina". Não é uma postura fácil de ser sustentada publicamente, sobretudo para um arquiteto português com pouco mais de 20 anos. Mas como ele mesmo dirá alguns anos depois, em entrevista a Luis Santiago Batista e Margarida Ventosa, "a crítica é relevante quando exprime a consciência de um exílio".

Esta e outras passagens brilhantes estão no capítulo "Arquitectura" , o mais encorpado do livro, onde encontra-se também um dos registros mais surpreendentes: uma troca de correspondência com Nuno Faria e André Maranha por meio da qual se vai montando o programa de um seminário sobre a arquitetura do confinamento realizado em 2003 na Universidade Autónoma de Lisboa, onde Diogo foi professor. A proposta, da qual o autor se torna uma espécie de cúmplice, bem poderia estar no inventário das "pedagogias radicais" conduzido por Beatriz Colomina na Universidade de Princeton, tal é o grau de experimentação e liberdade dos modos de ensino praticados: uma espécie de jogo em que os alunos e alunas são destinatários de cartas escritas periodicamente por remetentes que nunca encontram, e que contém o enunciado de cada aula.

Merece destaque ainda a seção "rossiana", que reúne textos desenvolvidos no âmbito dos estudos de doutoramento de Diogo na ETH-Zurich, concluído em 2013 sob orientação de Vittorio Magnano Lampugnani, do qual resultou o livro "Melancholy and Architecture: On Aldo Rossi" (publicado originalmente em inglês, em 2015, pela Park Books, e em seguida traduzido e publicado em português pela editora Orfeu Negro).

Na verdade, são tantos os textos, temas e objetos em jogo que qualquer leitor mais dedicado logo sentirá a falta de um índice onomástico. Sem ele, fica um pouco difícil se mover no espaço denso do arquivo, sobretudo para quem não tem familiaridade com o seu conteúdo ou busca uma referência mais precisa. Talvez esta dificuldade tenha sido pensada em contraponto à acessibilidade prometida pelos dispositivos atuais 
de leitura. Mas o risco é também afastar o leitor que gostaria de identificar quais foram os arquitetos e arquitetas - ou cineastas, ou bandas punk - que mais ocuparam o autor. Ou ainda localizar suas referências à arquitetura brasileira, por exemplo, para além da imagem de Vilanova Artigas que se deixa entrever num texto de 2012 dedicado ao arquiteto português Ricardo Bak Gordon.

Mais que uma homenagem, de todo modo, o livro revela-se também um dispositivo de promoção - de um autor português, é certo, mas também de um círculo intelectual que vem trabalhando pela inscrição de Portugal no complexo contexto global atual, sem qualquer ranço nacionalista. Isso ajuda a entender a decisão de dar ao livro um caráter monumental, ainda que à custa do seu manuseio e leitura. Bem como a decisão de manter alguns textos em inglês, no idioma em que foram escritos. Mas este livro talvez seja também estrategicamente ilegível. Afinal a constituição do arquivo é também um manifesto, que neste caso assume papel-chave dentro de um projeto político-intelectual bem mais amplo.

No campo da crítica arquitetônica, não são muitos os autores que dispõem de uma publicação deste porte, na linha dos assim chamados "hefty books" ou "fat books". Rem Koolhaas, com $S, M, L, X L$, Daniel Libeskind, com Red is not a colour, são os nomes que primeiro vem à mente quando se toma o volume em mãos: um bloco de 856 páginas, capa dura e dimensões avantajadas $(21,6 \times 26,2 \mathrm{~cm})$, de peso e formato equiparáveis a um tijolo cerâmico $(2,4 \mathrm{~kg})$. Seria possível também estabelecer um paralelo com o Registro de uma vivência, de Lucio Costa. Não deixa de ser curioso, em todo caso, que o livro mostre semelhanças ainda com outra publicação simultânea em Portugal: o catálogo da retrospectiva de Eduardo Souto de Moura na Casa da Arquitectura ("Souto de Moura: Memória, Projectos, Obras", com curadoria de Francesco Dal Co e Nuno Graça Moura). E apesar de não haver qualquer relação entre as duas produções, não deixa de ser curioso que ambas as publicações tenham ficado a cargo da mesma dupla de designers - Lizá Defossez Ramalho e Artur Rebelo, do studio R2 -, além de terem sido impressas simultaneamente na mesma tipografia portuense. Sendo que o livro de Seixas Lopes - produzido por uma pequena e jovem casa editorial, que se apresenta como "uma editora de vão-de-escada" - tem exatas 344 páginas a mais que o de Souto de Moura, editado em parceria pela Casa da Arquitectura e Yale University Press. O que já diz alguma coisa, sobretudo quando se tem 
em mente as diferenças entre os dois arquitetos, em todos os sentidos.

Na verdade, mesmo fora de Portugal, talvez não haja precedentes para um autor tão jovem. Nem para um livro que é mais de crítica que de projeto. É curioso pensar que, seja por um motivo ou por outro, a obra fundamental de Manfredo Tafuri, por exemplo, ainda não foi reunida num livro assim. A de Aldo Rossi tampouco. A de Kenneth Frampton também não. E - Arquivo Seixas Lopes existiria, se não fosse obra póstuma? Como esclarece o próprio editor, "em nenhuma circunstância Seixas Lopes teria feito um livro assim." Teria cortado mais, editado mais, enfim, teria sido mais seletivo e implacável consigo próprio. $\mathrm{E}$ aqui voltamos a um ponto que parece ter sido crucial para a definição do projeto editorial: o livro tem caráter monográfico, mas não é obra de um autor só.

Além da dimensão editorial propriamente dita, a publicação só existe por conta de um laborioso trabalho de investigação que se estendeu por 2 anos, mobilizou uma vasta rede de amigos, colaboradores e ex-alunos e alunas de Diogo e recebeu apoio de um conjunto expressivo de instituições portuguesas: Universidade do Minho, Fundação Calouste Gulbenkian, Direção-Geral das Artes, Trienal de Arquitetura de Lisboa, Centro Cultural de Belém, Cinemateca Portuguesa, Fundação para a Ciência e Tecnologia e União Europeia.

Ainda assim, é inevitável perguntar-se qual é (ou será) o público deste livro. Grande demais para ser lido, pesado demais para ser transportado ou despachado, caro demais para o bolso de um estudante, assume sem dúvida decisões editoriais arriscadas, como outros livros da mesma editora (em particular, o genial Eduardo Souto de Moura: Atlas de Parede, Imagens de Método, editado por Pedro Bandeira e André Tavares, 2011). Mas - e isso é o mais importante - mostra um sinal de vitalidade num meio que apesar das suas evidentes qualidades, corre o risco maior da estagnação. 